\title{
Concepção dos Professores do Curso de Medicina da Universidade Federal de Santa Catarina sobre o Sistema Único de Saúde*
}

\author{
The Unified National Health System in \\ Brazil as Viewed by Faculty Members from \\ the School of Medicine at the Federal \\ University in Santa Catarina.
}

\author{
Flávia Henrique' \\ Marco Aurélio Da Ros ${ }^{2}$
}

PAI AVRAS-CHAVE:

- Recursos humanos em Saúde;

- Pulícica de Saúde;

- Educação Médica;

$-S U S$ (BR).

KEL:-WV DRISS

- Health Manpower:

- Health P'olicy

- Malucariun, Medical;

$-S L S(B R)$

Recelbidn cni: 13/(1)5/2003

Reaxiamial zultuctsa $(18 / 09 / 2003$

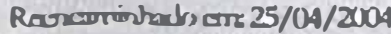

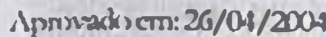

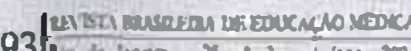

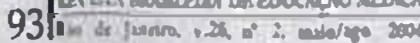

\section{RESUMO}

A implementaçuo efetiva do Sisterna Único de Saude (SLiS), que nasce com a Constituiçäo de 1988, incressita, entre outros premissals, da capacitaça de recursos humanos. Conforme a Lei de Divetrizes Curricularc.s de 2001 pasa o curso de modicina, há uma determinaģa de que a formaģa académica deve ser pautada pelos principios do SUS e se voltar para suprir a necessidade deste sistenta com resolutividade e qualidade Segundo o relatorio da Cinnem, um dos principais cheterminantes da for-

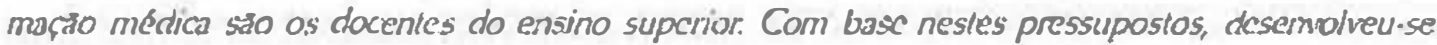
uma pesquisa na Unniersidade Feck:ral de Santa Catarina, corn o objelivo de compreender as concepfares dos professores de modicina acerca do SUS. Nesta pesquisa. foi utilizado o método qualitatives. que se bascou na anslise do conteúdo de fala de nove entrevistodos e possibilitou a observaça de

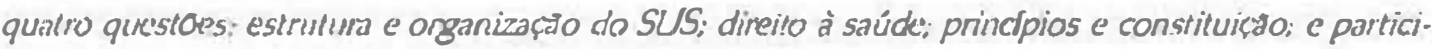

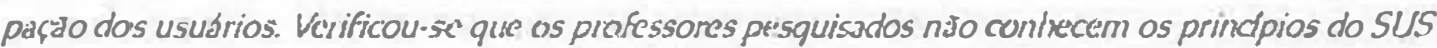

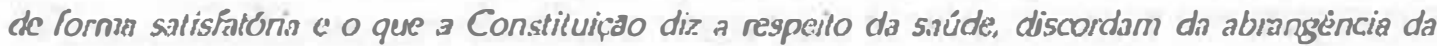
alencrao ofenecida peto SUS e desconhecem ermo se dá o contrule social do sistema.

\section{ABSTRACT}

Brozil's Unified National Health System (SLIS), created uncker the 1988 Ferderal Constitution, calls for the training of requisite human ressounces for the system's effectrive implementation, among other

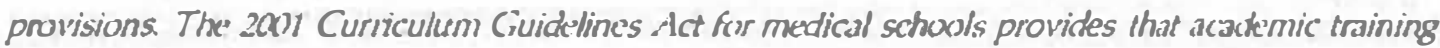
steuld be bused on the principle!s laid out for the National Health System and should be fox usxid on nketing the System's ixeds in terms of case-sescohing capacity and quality. Acconding to the (INA-

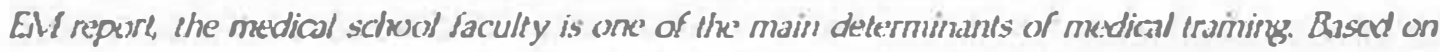
thessc premises, a study s was conducted at the fectcral Universily in Santa Catasina. ainked al understanding medical professors' concepls concerning the Nistional Health System. The study used a qualitative me:lkadology based on anatysis of discourse conte'nt fron sirne intervienees and highlighting lour k'y issek's: the struture and onganization of the National Health Systen); the right to Ixealth; prixciphes and constifution; and participastion by the System is clients. According to the study, the nkedical school professon intervievind wen: unfamiliar with evither the National Health Systerm is pirincipk's or the Ceanstitutional provisions in relation to health, while disagrecing with the scope or ange of care prosided by the National System and igswring luw social control of the System operates.

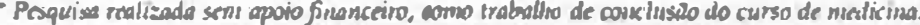

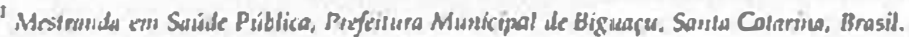

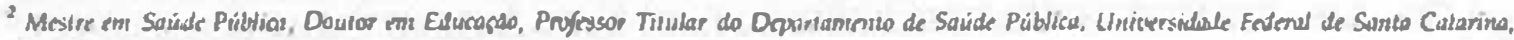
Floniarópolis, Brasil 


\section{INTRODUÇÃO}

A Constituiçảo Federal brasileira de 1988 instituiu o Sistema Único de Saúde (SUS), como resultado da intensa luta do movimento pela reforma sanitária, que tem como premissa oferecer saúde de qualidade a todos os brasileiros ${ }^{1}$. Em 15 anos de existência, mesmo apresentando alguns avanços e bons resultados, o SUS ainda está muito distante do que pretendem seus princípios básicos ${ }^{2}$.

Sảo várias as possiveis explicações para a não implementação do SUS tal como idealizado no texto constitucional de 1988 e nas leis orgânicas de 1990, entre elas: a falta de financiamento para o sistema; a centralizaçāo de programas que não levam em conta as diferenças locais; a falta de uma política efetiva de medicamentos; o número insuficiente de trabalhadores capacitados ${ }^{3}$. Uma questão levantada repetidas vezes é a da capacitação de profissionais para o SUS, especialmente dos médicos ${ }^{4.5}$. Esta vem sendo alvo de debates em várias organizações, como sindicatos, universidades, movimento estudantil e governo, que apontam a necessidade de formar um novo perfil profissional que atenda a demanda do SUS com resolutividade e qualidade.

Neste sentido, várias ações foram tentadas e passos importantes foram dados para colaborar com a modificaçāo deste panorama, como a formação da Comissão Institucional Nacional de Avaliaçāo do Ensino Médico (Cinaem) em $1991^{6}$. Os relatórios dessa comissão têm oferecido uma importante contribuição para o entendimento da situaçāo do ensino médico no Brasil.

Houve outros avanços, como, por exemplo, a criação das Diretrizes Curriculares Nacionais para todos os cursos da área da saúde, inclusive a medicina, que reafirmou a necessidade de a formaçāo acadêmica ser pautada e direcionada para o SUS - "vincular, através da integraçāo ensino-serviço, a formação médico-acadêmica às necessidades sociais em saúde, com ênfase no SUS"

Para assegurar o financiamento necessário à implementação efetiva das propostas contidas nas novas diretrizes curriculares, criou-se o Programa de Incentivo a Mudanças Curriculares nas Escolas Médicas (Promed), que financia cursos que apontam em direção à atenção básica do $\mathrm{SUS}^{8}$.

O consenso aparente em torno da necessidade de alterações curriculares demanda, por outro lado, a identificaçāo dos pontos falhos no processo de formação dos profissionais médicos. Cumpre, assim, entender os aspectos determinantes da educaçāo médica no Brasil.

O relatório da Cinaem, mencionado acima, apresenta como principais determinantes da formação os recursos humanos e o modelo pedagógico adotado em cada escola. As- sim, é de extrema importância compreender como pensam e agem os educadores das escolas médicas.

Este estudo foi realizado como uma contribuiçāo para o desvelamento deste pensar e agir dos professores, objetivando auxiliar a compreensão das concepções e conhecimentos que professores do curso de medicina da Universidade Federal de Santa Catarina possuem acerca das diretrizes do Sistema Único de Saúde, no sentido de colaborar para o entendimento do processo de formação de estudantes e do perfil do médico formado.

\section{MÉTODOS}

Segundo a experiência dos orientadores desta pesquisa, concepçōes e conhecimentos são mais bem avaliados por meio da análise da profundidade do discurso. Assim, foi utilizado o método qualitativo com análise do conteúdo de fala ${ }^{29.10}$.

O número de entrevistados em uma pesquisa qualitativa depende da exaustão das respostas encontradas, ou seja, a repetição das respostas de mesmo teor permite aprofundar os significados das mesmas".

Para testar a forma de abordagem junto aos professores, realizamos um pré-teste com três docentes da Faculdade Regional de Blumenau. Esse pré-teste continha uma só pergunta aberta, que deixou margem a diferentes interpretaçzes. Várias questōes que esperávamos fossem abordadas não surgiram. Assim, optamos pela entrevista semi-estruturada de acordo com um roteiro preestabelecido.

Fez-se um levantamento minucioso de todos os professores que lecionam no curso de medicina, seus telefones de contato e respectivos departamentos de atuação junto à Coordenadoria do curso. Então, foi realizado um conta to com os professores escolhidos. Para que a amostra fosse o mais representativa possivel, foram selecionados 20 possiveis entrevistados, considerados pelos pesquisadores/orientadores como representativos dos estilos de pensamento de seus departamentos, assim distribuídos: cinco do departamento de Clínica Médica, cinco do Departamento de Clínica Cirúrgica, trés do Departamento de Gineco-Obstetricia, três da Pediatria, um da Saúde Pública e três das áreas básicas.

Iniciou-se o roteiro de entrevistas com um professor de cada área e um do ciclo básico. Pelo critério utilizado, de saturaçāo das respostas encontradas, finalizou-se a amostra com o número de nove entrevistados, que abrangiam todos os departamentos mencionados.

Cada professor pesquisado foi caracterizado como informante 1, 2,3, e assim por diante, segundo a ordem de realização das entrevistas, para preservar a identidade de cada docente. 
A entrevista completa contém os seguintes tópicos: organizaçāo, estrutura e funcionamento do SUS; direito à saúde; principios e constituição do SUS; e controle social do sistema.

Esta pesquisa foi realizada sem apoio financeiro, como trabalho de conclusāo do curso de medicina.

\section{RESULTADOS E DISCUSSĀO}

\section{Organização, Estrutura e Funcionamento do SUS}

Ao serem questionados acerca da organizaçāo, estrutura e funcionamento do sistema, alguns docentes se restringiram a julgar o SUS:

Sei que ndo funcionn, o sistema de saride tem posto de saúde para o atendimen to básico da populaçāo, hospitais puiblicos mais especializados, hospitais clinicos e a rede particular. (inf. 2)

Outros professores somente dividiram o sistema em público e privado, sem fazer consideraçōes sobre como se estrutura ou se organiza:

O sistema de saide do Brasil $\mathfrak{E}$ dividido em duns partes, tem a parte privada, que é a parte particular de cada profissional, através de consultórios em hospitais que também muitas vezes sño particulares (...). (inf. 3)

Eu dividirin o sistema de saúde basicamente em dois sistemas, o sistema puiblico ou previdenciário, e o sistema privado on de mútuns ou seguro. O sistema previdenciário seria basicamente representado pelo SUS, e o sistemn que oferece em alguns locais do pais, principalmente na Regiño Sul e também na Regin̄o Sudeste, condiçðes para que a maior parte da populaçño possa ser atendida $\mathrm{cm}$ doenças importantes, entretanto é muito defasado o SUS erm várias áreas da medicina (...). (inf. 7)

Esses professores, no entanto, não mencionaram a relação de complementaridade que o setor privado deve ter com o público.

Quanto à organizaçāo e hierarquizaçảo do sistema, percebe-se que a maior parte dos professores apenas cita superficialmente estas questòes:

Se estruturn en centros de referêncin e contra-referência, entño tu tens uns centros que, organizados por bairros, os PAMs, os postos de saude que fazem aquele atendimento básico, da triagem básica, tem alguns centros de referência para algumas patologias. (inf. 4)
Nenhum dos professores, porém, conseguiu responder como se dá a descentralizaçāo, a hierarquização do sistema e a complementaridade do setor privado, conforme preconizado nos principios do SUS.

Muitas vezes, os professores ainda fazem uso de certas terminologias, como "PAMs" e "sistema previdenciário", que remontam ao antigo e extinto Instituto Nacional de Assistência Médica da Previdência Social, demonstrando que não acompanharam as transformaçōes do sistema de saúde.

\section{Direito à Saúde}

A reposta acerca do direito à saúde demonstrou que há professores que desconhecem o direito uni versal e equânime de todos os brasileiros à saúde:

Sei que em hipótese todo cidadāo tem acesso, direito e acesso a um sistema basico de saíde (...). (Inf. 2)

A maior parte dos entrevistados reconheceu que a Constituição assegurava algum direito à saúde, embora sem definir claramente o que era isso. Porém o que chamou a atençāo foi o fato de que nem todos concordaram com ele:

Eu acho que o serviço de saide deveria ser pago para quem tem dinheiro, gratuito desde internaçño, remédio e transporte para pessons que nño têm dimheiro e serem atendidas no mesmo sistema, mas o pobre uño deveria pngar e o rico com condiçỏes para pagar deveria pagar. (inf, 6)

Olha, pela Coristituiçño todo muudo tem direito, só que o que eu achoé que a gente tem que bolar o pé no chīo para o que o SUS pode fornecer (...). Acesso temt que ser global, mas de saúde brisica (...). (inf. 3)

Esta forma de conceber o sistema de saúde com universalidade sem eqüidade ou integralidade denonstra o posicionamento de alguns professores em desacordo com os principios do SUS. Isto nos faz pensar que eles podem cultivar tal descrédito em relaçāo ao sistema com os estudantes, sem discutir a viabilidade teórica frente à disponibilidade de recursos, entre outras questōes, que podem ser limitantes para a implementaçāo do sistema. Isto nāo precisa, necessariamente, ser conteúdo curricular, mas pode aparecer na forma de "curriculo oculto", na terminologia de Apple".

\section{Principios e Constituiçāo do SUS}

Outra pergunta dizia respeito aos princípios e à Constituição. Vários entrevistados declararam não saber o que dizem os princípios ou a Constituiçāo a respeito do SUS: 
Acho que não sei bem o que a Constituição diz a respeito da saúde. (inf. 2)

Eu desconheço os meandros desses princípios, mas, pelo que a gente vê na prática, não conheço, mais que está executado ali, o que a gente vê é que o médico tem que atender um número xis de doentes (...). (inf. 5)

Olha, sinceramente, eu desconheço como é feita a hierarquização do SUS, do que eu tenho idéia a tendência é municipalizar esse atendimento à saúde. (inf. 7)

Eu desconheço, em profundidade. Eu desconheço. Não tenho maiores conhecimentos. (inf. 9)

Três entrevistados não deixaram claro se compreenderam o que foi perguntado, pois não discutiram o conteúdo da pergunta, apenas afirmaram que teoricamente concordavam, mas na prática não funcionava. Entretanto, se contradiziam quando tentavam explicar por que não funcionava ou forneciam explicações simplistas:

Os princípios do SUS, teoricamente, né. Na prática, é uma coisa, na teoria é outra, na teoria não tenho nada contra, na prática eu acho que as coisas não podem ser privilégios de algumas pessoas, isso não pode, quando a gente está falando de saúde pública nós temos que dar o básico (...). (inf. 3)

Teoricamente, ótimo, mas na prática não funciona, é por desonestidade do farmacêutico, desonestidade do atendente, do médico, e aí vai... o atendente no posto de saúde diz que o médico só vai aparecer das cinco para as onze às onze e trinta, a enfermeira que năo aparece, ocorre troca de atendente dia sim dia não, d̀s vezes tem a medicação e diz que nāo tem para não trabalhar, falta educação e motivação (...). (inf. 6)

Os princípios do SUS estāo corretíssimos desde que o País seja sério; no nosso caso, em que o País não é sério, então, embora a legislação esteja toda bem montada, na prática não funciona. (inf. 8)

Alguns informantes deram respostas vagas, sem relação com a pergunta, o que nos faz supor que não compreenderam o que foi perguntado ou não sabiam do que a pergunta tratava:

Eu acho que aquele sistema de saúde básico está pecando em tudo, porque basta ver um paciente às vezes que não tem condições, sobretudo intelectuais, você vê que ele é enrolado, jogado de um lado para outro (...). (inf. 4)
Uma das repetições mais encontradas coloca em xeque o princípio da eqüidade e integralidade:

Sei que em hipótese todo cidadão tem acesso, direito e acesso a um sistema básico de saúde (...). (inf. 2)

Olha, pela Constituição todo mundo tem direito. Só que o que eu acho é que a gente tem que botar o pé no chão para o que o SUS pode fornecer (...). Acesso tem que ser global, mas de saúde básica (...). Os princípios do SUS, teoricamente, né, na prática é uma coisa, na teoria é outra, na teoria não tenho nada contra, na prática eu acho que as coisas não podem ser privilégios de algumas pessoas, isso não pode, quando a gente está falando de saúde pública nós temos que dar o básico (...). (inf. 3)

Existe entre os entrevistados a compreensão de que apenas o sistema de saúde básico deve ser público, contrariando o princípio da integralidade do sistema, reservando somente àqueles com condições socioeconômicas favoráveis a possibilidade de atendimento integral e equânime.

\section{Controle Social do SUS}

Sobre o questionamento acerca de como as pessoas devem se organizar para reivindicar melhores condições de saúde, apenas dois dos entrevistados citaram a figura do conselho de saúde:

Existe a comissão municipal de saúde, o conselho municipal de saúde, o conselho estadual de saúde e o conselho federal de saúde; então, no conselho municipal de saúde deveriam participar das reuniōes todos os cidadãos que são atingidos da unidade sanitária para levarem as suas reivindicaçōes (...). (inf. 8)

Pessoas da comunidade integram o conselho, não sei bem como as pessoas são escolhidas, mas sei que no município são o prefeito, o secretário municipal de saúde e um conselho de pessoas da comunidade, líderes comunitários provavelmente. (inf. 1)

Analisando as outras respostas, descobrimos como se dá o controle social para um dos entrevistados:

Isso acho que é na eleição, colocar pessoas boas, que tenham capacidade de gerenciar, não vejo outra coisa. (inf. 3)

Percebe-se que, para ele, o cidadão só pode participar passivamente do sistema de saúde, por meio das eleições.

A maior parte dos entrevistados respondeu que as pessoas devem se organizar por meio de reuniōes em bairros ou hospitais: 
Em agremiaçōes das comunidades, em associaçōes de bairro, em associação seja ela qual for, e juntos cobrar do poder público (...). (inf. 2)

Eu acho que a coisa começa com a consciência do bairro, o líder da comunidade faz uma reunião com o pessoal do bairro e exige da prefeita, do prefeito, aquilo que está previsto (...). (inf. 5)

Talvez se pudesse montar reuniões em hospitais como se faz com grupo de diabéticos, grupo de gestantes, etc., retirar alguns lideres e fazer algum tipo de movimento, exigir algo melhor para a população. (inf. 7)

Eu acho que tudo parte da consciência, de um trabalho de consciência, até mesmo de cada cidadão pelos seus direitos, lutar por seus direitos, se organizando em comunidades, representantes da comunidade; eu acho que a necessidade de um local em termos de saúde pode ser diferente de outro: um precisa saneamento básico, trabalhar essa parte, outros precisam mais de outros aspectos da saúde, talvez um mais na pediatria, outro mais na ginecologia. (inf. 9)

A maioria dos entrevistados, no entanto, nāo fez referência aos conselhos de saúde, demonstrando o distanciamento destes professores em relação ao órgão legítimo de planejamento das ações em saúde, que reserva um percentual de vagas diretamente aos trabalhadores da saúde.

Em nenhuma das respostas, nem entre os professores que demonstraram conhecer o conselho de saúde, foi citada a participação do profissional de saúde como um agente ativo no processo de planejamento, avaliação e transformação do sistema de saúde, permitindo inferir que a categoria médica desconhece, inclusive, a sua possibilidade de interferir nas mudanças.

Interessante observar que a resposta de um dos informantes levava a crer que somente pessoas com cargos de direção poderiam modificar o sistema:

Eu conheço poucas pessoas, não tenho noçāo para te dizer isso ai, as pessoas que são meus superiores no lugar em que trabalho são pessoas que sempre atuaram com muito boa vontade, dignamente, nunca que vi nada que pudesse ser contra qualquer procedimento deles, muito pelo contrário, a gente vê que eles querem arrumar as coisas, mas a gente vê que os problemas são acima deles e aí eles têm as mesmas dificuldades que nós. (inf. 3)

Outra resposta que chama atenção se refere à participação do professor/profissional de saúde:
$\hat{E}$ dificil isso de te responder. Acho que uma população se organizar, acho que tem que existir um conhecimento de como funciona; eu, que trabalho na área da saúde, sou médico e desconheço basicamente os princípios do SUS, imagine um trabalhador que ganha um salário mínimo e tem quatro filhos para sustentar, como ele vai conseguir ter uma informação desse tipo (...). (inf. 7)

Assim, fica claro que a maior parte dos professores desconhece a existência de conselhos de saúde, a representatividade dos profissionais e sua importância para o avanço do sistema. Isto leva a crer que questões como legislação, regulamentação, organização e participação no sistema não têm significado frente a sua prática como professores e profissionais. Neste último caso, infere-se que seja uma prática liberal ou alternada.

\section{CONSIDERAÇÕES FINAIS}

Com base neste estudo exploratório, percebe-se que os professores necessitariam de atualização e aprofundamento nos conhecimentos referentes aos princípios e à organização do SUS.

Acreditamos que somente se conhecerem seus direitos e deveres na qualidade de usuários e profissionais de saúde é que eles irão se incluir nas organizações que, junto às comunidades e aos conselhos de saúde, buscam melhorar o sistema.

Sensibilizados para a importância do profissional/professor da área da saúde como agente de construção de consciência crítica acerca das questōes relacionadas à saúde, eles poderiam transmitir essas informações, fundamentais à formação dos estudantes de medicina, inclusive porque implicam o futuro concreto e imediato que os espera após formados.

Parece-nos importante alertar que, para as modificações curriculares e Promeds, não bastam metodologias criativas; é preciso preparar os professores no entendimento e adesão ao SUS, para que possam preparar os futuros profissionais de forma diferente.

\section{REFERÊNCIAS BIBLIOGRÁFICAS}

1. Escorel S. Reviravolta da Saúde: origem e articulação do movimento sanitário. Rio de Janeiro: Editora FIOCRUZ; 1998.

2. Ros MAD. Estilos de pensamento em saúde pública: um estudo da produção do FSP-USP e ENSP-FIOCRUZ entre 1948 e 1994, a partir da epistemologia de Ludwik Fleck. 207 p. [Tese] Florianópolis, Doutorado em Educa- 
ção e Ciência, Universidade Federal de Santa Catarina, 2000.

3. Ros MAD. Fórum popular estadual de saúde: Expressão catarinense do Movimento Sanitário para os anos 90. Florianópolis (SC): [.s.n.]; 1994. p.18.

4. Feuerwerker LCM. Diversificação de cenários de ensino e trabalho sobre necessidades/problemas da comunidade: Saúde em Debate 2000; 55: 92-103.

5. Machado MH. Os médicos no Brasil: um retrato da realidade. 20 ed. Rio de Janeiro: Editora FIOCRUZ, 1997. 244 p.

6. Cinaem. Avaliação do Ensino Médico no Brasil: Relatório Geral. [s.l.: s.n.]; 1997.

7. Brasil. Ministério da Educação. Conselho Nacional de Educação. Diretrizes Curriculares Nacionais dos Cursos de Graduação em Medicina. Brasília. Parecer n. 1.133 de ago 2001.

8. Brasil. Ministério da Saúde. Informe Saúde. Lançado o programa para mudar currículo de medicina. 2002; VI(158): abr.

9. Cutolo LRA. Estilo de pensamento em educação médica: um estudo do currículo do curso de graduação em medi- cina da UFSC. [Tese], Florianópolis, Doutorado em Educação, CED, Universidade Federal de Santa Catarina, 2001. $208 \mathrm{p}$.

10. Minayo MCS. O desafio do conhecimento: pesquisa qualitativa em Saúde. 3 ed. São Paulo, Rio de Janeiro: Hucitec/ Abrasco; 1994.

11. Apple M. Ideologia e currículo. São Paulo: Brasiliense; 1982.

12. Bardim L. Análise de conteúdo. Reto LA; Pinheiro A (trades). Análise de conteúdo. São Paulo: Ed. 70. 1977.

\section{Endereço para correspondência}

Flávia Henrique

Morro do Mocotó 125 - Prainha

88020-200 - Florianópolis - SC

E-mail:fabflavi@yahoo.com.br

Marco Aurélio Da Ros

Estrada da Praia Mole, 1.750 — Lagoa da Conceição 88062-970 - Florianópolis - SC

E-mail: ros@ces.ufsc.br 